\title{
Pulmonary sclerosing hemangioma with lymph node metastasis: A case report and literature review
}

\author{
YASUSHI ADACHI ${ }^{1,2}$, KOJI TSUTA $^{3}$, RYUJI HIRANO $^{4}$, JIN TANAKA $^{4}$, \\ KEIZO MINAMINO ${ }^{5}$, TOMOHIKO SHIMO ${ }^{6}$ and SUSUMU IKEHARA ${ }^{2}$ \\ ${ }^{1}$ Division of Surgical Pathology, Toyooka Hospital, Toyooka, Hyogo 668-8501; ${ }^{2}$ Department of Stem Cell Disorders, \\ Kansai Medical University, Hirakata, Osaka 573-1010; ${ }^{3}$ Department of Pathology and Clinical Laboratories, \\ National Cancer Center Hospital, Tokyo 104-0045; ${ }^{4}$ Division of Thoracic and Cardiovascular Surgery, \\ Toyooka Hospital, Toyooka, Hyogo 668-8501; Departments of ${ }^{5}$ Ophthalmology and ${ }^{6}$ Pediatrics, \\ Kansai Medical University, Hirakata, Osaka, Japan
}

Received July 2, 2013; Accepted December 16, 2013

DOI: 10.3892/ol.2014.1831

\begin{abstract}
Pulmonary sclerosing hemangioma $(\mathrm{SH})$ is an uncommon benign or low-grade malignant tumor. Multicentric $\mathrm{SH}$ and $\mathrm{SH}$ with lymph node metastasis have rarely been reported. The present report describes a case of pulmonary $\mathrm{SH}$ with lymph node metastasis in a middle-aged female. A nodule was found incidentally in the lower left lung. The patient underwent left lower pulmonary lobectomy and lymph node dissection. Histologically, the nodule demonstrated the characteristic features of SH and one of the resected lymph nodes contained a metastasis of this tumor. Thus, pulmonary SH has the potential to metastasize, a potential not suggested by histological features.
\end{abstract}

\section{Introduction}

Sclerosing hemangioma ( $\mathrm{SH}$ ) of the lung is an uncommon tumor that was first described by Leibow and Hubbell in 1956 (1). SH is a lung tumor with a distinctive constellation of histological findings, including solid, papillary, sclerotic and hemorrhagic patterns (2). SH usually presents as a slow-growing benign mass in the lower lobes of middle-aged females (3). Several reports have described multicentric SHs or SHs with lymph node metastasis (4-19). Thus, SH is not always benign and it has the potential to metastasize.

\section{Case report}

Clinical summary. A 40-year-old female was referred to Toyooka Hospital (Toyooka, Hyogo, Japan) after chest X-ray screening revealed a nodule in the left lower pulmonary field.

Correspondence to: Professor Susumu Ikehara, Department of Stem Cell Disorders, Kansai Medical University, 2-5-1 Shinmachi, Hirakata, Osaka 573-1010, Japan

E-mail: ikehara@hirakata.kmu.ac.jp

Key words: sclerosing hemangioma, lymph node metastasis, lung, middle-aged female
The patient had no history of smoking. Family history was negative for relevant diseases. Blood tests revealed no increase in concentrations of tumor markers.

Chest computed tomography (CT) scanning revealed a nodule $\sim 10 \mathrm{~mm}$ in diameter in the left lower lung (Fig. 1), but no mediastinal or hilar lymph node swelling. The patient underwent lobectomy of the left lower lung with lymph node dissection.

Pathological findings. Macroscopically, the tumor was sharply demarcated from the surrounding lung tissue and $\sim 10 \times 10 x 10 \mathrm{~mm}$ in size (Fig. 2A). The cut surface was whitish and sclerotic.

Microscopically, the tumor demonstrated various features characteristic of $\mathrm{SH}$, including angiomatoid areas, sclerosis, papillary structures lined with cuboidal cells and sheets of round to polygonal cells with slightly eosinophilic cytoplasms.

Immunohistochemically, the surface-lining cells were positive for napsin A, cytokeratin AE1/AE3 (Fig. 3) and cytokeratin 7 (data not shown). The other cells were negative for these markers. However, all the tumor cells (both the surface-lining and polygonal cells) were positive for thyroid transcription factor 1 (TTF-1), which is expressed not only in thyroid epithelial cells but also in type II pneumocytes and Clara cells, and epithelial membrane antigen. These findings suggested that the tumor was an $\mathrm{SH}$.

A small metastatic focus of $\mathrm{SH}$ was identified in one mediastinal lymph node. This lesion shared the papillary pattern of the primary tumor and was TTF-1-positive (Fig. 4). The patient provided written informed consent. This study was approved by the Ethics Committee of Toyooka Hospital (Toyooka, Japan).

After two years of follow-up the patient has not exhibited any recurrence nor metastasis of the tumor.

\section{Discussion}

Pulmonary SH was originally thought to be derived from the endothelium due to histological similarity to cutaneous $\mathrm{SH}$ (1).

In the present literature review, PubMed and JDream III (http://jdream3.com/) were used to search for studies written 
Table I. Cases of pulmonary sclerosing hemangioma with lymph node metastasis.

\begin{tabular}{|c|c|c|c|c|c|c|c|c|}
\hline \multirow[b]{2}{*}{ No. } & \multirow[b]{2}{*}{$\begin{array}{l}\text { Age, } \\
\text { years }\end{array}$} & \multirow[b]{2}{*}{ Gender } & \multicolumn{2}{|c|}{ Primary tumor } & \multicolumn{3}{|c|}{ Metastases } & \multirow[b]{2}{*}{ Reference } \\
\hline & & & Location & Size, $\mathrm{mm}$ & $\begin{array}{l}\text { Lymph } \\
\text { nodes, } \mathrm{n}\end{array}$ & $\begin{array}{l}\text { Maximum } \\
\text { size, } \mathrm{mm}\end{array}$ & Location & \\
\hline 1 & 22 & M & $\mathrm{R}$ lower & 50 & 1 & 3 & Hilum & 6 \\
\hline 2 & 48 & M & $\mathrm{R}$ lower & 80 & 2 & 2 & Hilum & 7 \\
\hline 3 & ND & ND & ND & 35 & 2 & ND & Hilum & 8 \\
\hline 4 & 67 & $\mathrm{~F}$ & $\mathrm{R}$ lower & 90 & 5 & ND & $\begin{array}{l}\text { Hilum, } \\
\text { mediastinum }\end{array}$ & 9 \\
\hline 5 & 10 & F & $\mathrm{R}$ middle & 47 & 1 & 5 & Regional & 10 \\
\hline 6 & 45 & $\mathrm{~F}$ & R upper & 25 & 3 & 7 & Hilum & 10 \\
\hline 7 & 45 & M & L lower & 37 & 1 & 3 & Mediastinum & 10 \\
\hline 8 & 50 & $\mathrm{~F}$ & L lower & 15 & 1 & 12 & Intralobular & 10 \\
\hline 9 & 19 & M & L upper (lingula) & 30 & ND & ND & $\begin{array}{l}\text { Intrapulmonary, } \\
\text { intralobular }\end{array}$ & 11 \\
\hline 10 & 19 & F & L Lower & 100 & 11 & ND & $\begin{array}{l}\text { Intrapulmonary, } \\
\text { interlobular, hilum }\end{array}$ & 12 \\
\hline 11 & 37 & $\mathrm{~F}$ & L lower & 20 & 1 & ND & Saltcellar & 13 \\
\hline 12 & 35 & M & L lower & ND & 1 & ND & Mediastinum & 14 \\
\hline 13 & 23 & M & $\mathrm{R}$ upper & 90 & Multiple & ND & Hilum & 15 \\
\hline 14 & 24 & $\mathrm{~F}$ & $\mathrm{R}$ lower & ND & ND & ND & ND & 16 \\
\hline 15 & 35 & M & L lower & 33 & 2 & ND & Mediastinum & 17 \\
\hline 16 & 55 & M & $\mathrm{R}$ lower & 22 & 1 & ND & Intrapulmonary & 18 \\
\hline 17 & 38 & $\mathrm{~F}$ & L lower & 33 & 1 & ND & Intralobular & 19 \\
\hline 18 & 40 & F & L lower & 10 & 1 & 0.5 & Mediastinum & $\mathrm{PC}$ \\
\hline
\end{tabular}

F, female; M, male; L, left; R, right; ND, not described; PC, present case.

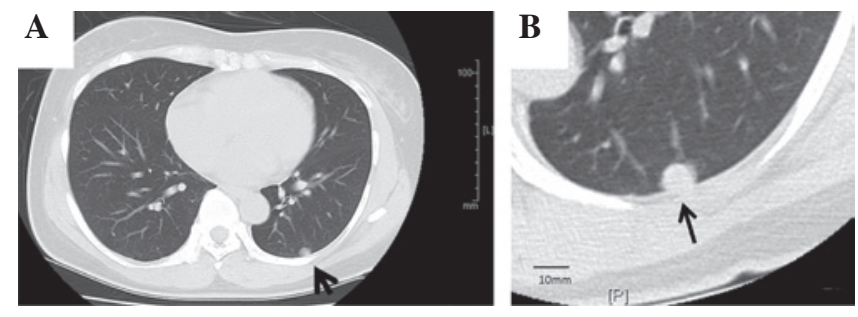

Figure 1. Computed tomography scan images of. (A) whole chest and (B) enlarged scan of the tumor.

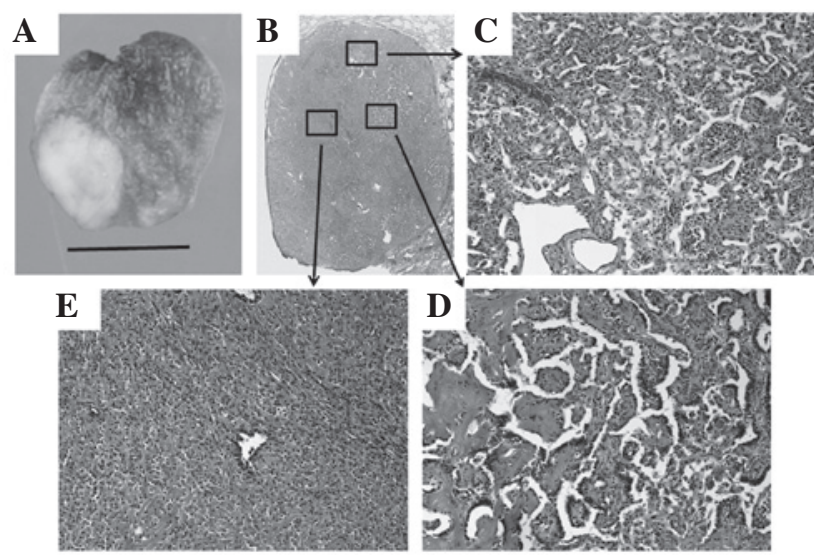

Figure 2. Macroscopic and microscopic findings. (A) Photograph of the tumor; (B) photograph of the tumor stained with hematoxylin and eosin captured through a magnifying glass; and (C-E) various microscopic features of the tumor (magnification, x20). 
Table II. SH cases and SH cases with lymph node metastasis.

\begin{tabular}{lcc}
\hline Parameter & SH $^{\mathrm{a}}$ & SH with lymph node metastasis $^{\mathrm{b}}$ \\
\hline Patients, $\mathrm{n}$ & 100 & 18 \\
Age, years (mean) & $13-76(46)$ & $22-67(36 \pm 15)$ \\
Gender, male : female & $1: 5$ & $8: 9$ \\
Primary tumor size, mm (mean) & $3-70(26)$ & $10-100(44.8 \pm 29.1)$ \\
Primary tumor location, $\%$ & 46 & 53 \\
Left lung & 54 & 47 \\
Right lung & 16 & 6 \\
Left upper lobe & 25 & 48 \\
Left lower lobe & 9 & 6 \\
Right upper lobe & 16 & 29 \\
Right middle lobe & 22 & 6 \\
Right lower lobe & & \\
\hline
\end{tabular}

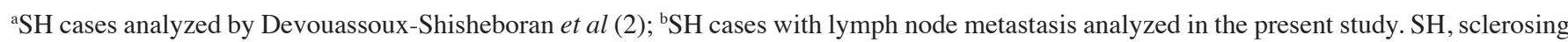
hemangioma.
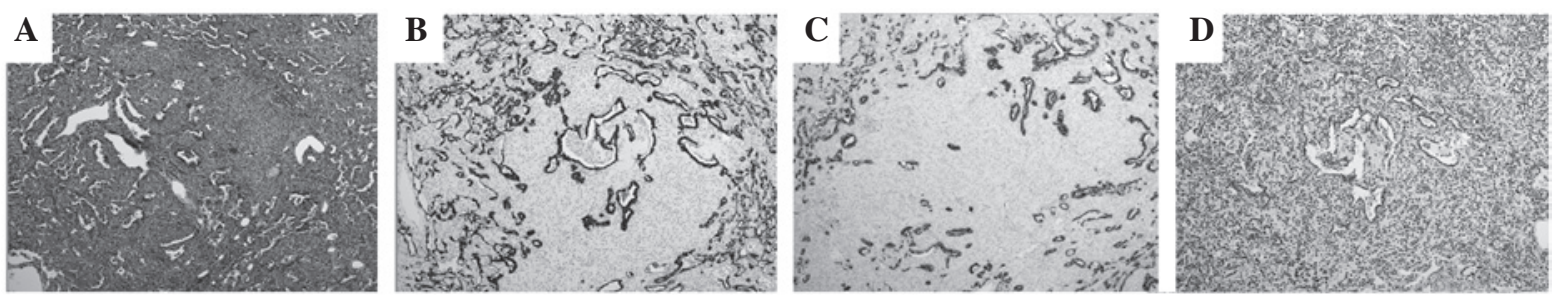

Figure 3. Immunohistological staining with (A) hematoxylin and eosin, (B) anti-napsin A antibody, (C) anti-cytokeratin AE1/AE3 antibody and (D) anti-thyroid transcription factor 1 antibody (magnification, x20).

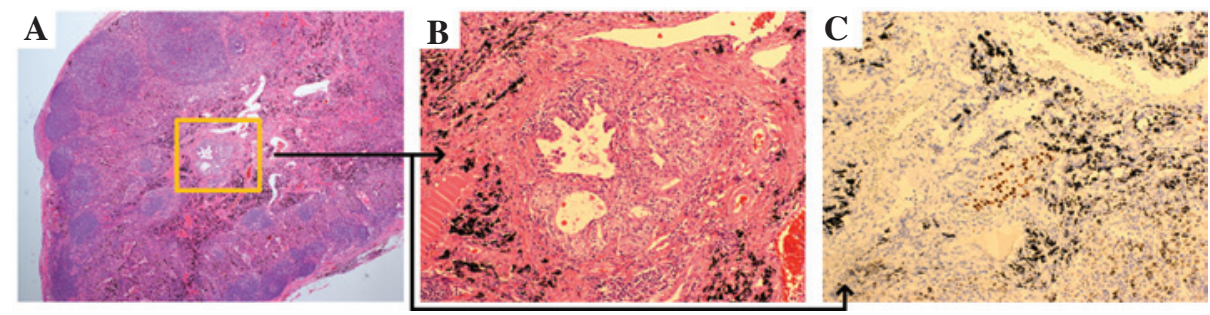

Figure 4. Lymph node metastasis of sclerosing hemangioma. (A) Photograph showing a mediastinal lymph node from the patient. Microscopic evaluation of the metastatic area with (B) hematoxylin and eosin staining and (C) staining with anti-thyroid transcription factor 1 antibody.

in English or Japanese reporting cases of pulmonary $\mathrm{SH}$ with metastasis in the lymph nodes, using the search terms 'sclerosing hemangioma', 'lung' and 'metastasis'. The results of these searches returned 17 such cases, of which 13 were in English and 4 in Japanese. Of the 4 studies written in Japanese, 3 cases were abstracts of congresses. Table I lists these cases, including the present report.

Analysis of the data provided in these reports revealed the following about $\mathrm{SH}$ with lymph node metastasis: i) The age of the patients ranged between 22 and 67 years [mean \pm SD, $36 \pm 15$ years]; ii) males accounted for $8 / 17$ cases $(47.1 \%)$ and females $9 / 17$ cases $(52.9 \%)$; iii) $9 / 17(52.9 \%)$ primary tumors were found in the left lung and $8 / 17(47.1 \%)$ were found in the right lung; iv) the left upper lobe was involved in $1 / 17$ cases
(5.9\%), the left lower lobe in $8(47.1 \%)$, the right upper lobe in $2(11.8 \%)$, the right middle lobe in $1(5.9 \%)$ and the right lower lobe in 5 (29.4\%); and v) the primary tumors ranged in size between 10 and $100 \mathrm{~mm}$ (mean, 44.8 $29.1 \mathrm{~mm}$ ).

Previously, Devouassoux-Shisheboran et al analyzed 100 cases of SH, including one with lymph node metastasis (8). In this study, the clinical and pathological features of these tumors were analyzed in detail. Patients ranged in age between 13 and 76 years (mean, 46 years). There were 83 female and 17 male patients; thus, the female-to-male ratio was 5:1. The left lung was the site of $46 \%$ of tumors (17\% in the left upper lobe, $25 \%$ in the left lower lobe, $1 \%$ in the fissure between the upper and lower lobe and the specific site was unknown in $3 \%$ of cases), and $54 \%$ were found in the right lung (9\% in the 
right upper lobe, $17 \%$ in the right middle lobe, $22 \%$ in the right lower lobe, $4 \%$ in the fissure between the middle and upper lobe, $1 \%$ in the fissure between the middle and lower lobe and the specific site was unknown in $1 \%$ of cases). The tumors ranged in size between 3 and $70 \mathrm{~mm}$ (mean, $26 \mathrm{~mm}$ ).

In the present study, the cases of $\mathrm{SH}$ with lymph node metastases that we compiled were compared with the cases of SH that Devouassoux-Shisheboran et al analyzed (8). As shown in Table II, SH with lymph node metastasis tended to occur more often in relatively young male patients than SH without metastasis. The mean size of primary SHs that had lymph node metastasis was larger than the mean size of non-metastatic primary SHs.

The findings that SHs with lymph node metastasis are larger and occur in younger patients may possibly correlate with the more rapid growth of these tumors. However, it is difficult to explain why there is a high frequency of SHs with lymph node metastasis in male patients and in the left lower lobe. Further investigation is required to elucidate the mechanism of metastasis of SH.

\section{References}

1. Liebow AA and Hubbell DS: Sclerosing hemangioma (histiocytoma, xanthoma) of the lung. Cancer 9: 53-75, 1956.

2. Devouassoux-Shisheboran M, Nicholson AG, Leslie K and Niho S: Sclerosing hemangioma. In: World Health Organisation Classification of Tumours: Tumors of lung, pleura, thymus and heart. Travis WD, Brambilla E, Muller-Hemelink HK and Harris CC (eds). IARC Press, Lyon, pp 115-117, 2004.

3. Keylock JB, Galvin JR and Franks TJ. Sclerosing hemangioma of the lung. Arch Pathol Lab Med 133: 820-825, 2009.

4. Maeda R, Isowa N, Miura H, Tokuyasu H, Kawasaki Y and Yamamoto K: Bilateral multiple sclerosing hemangiomas of the lung. Gen Thorac Cariovasc Surg 57: 667-670, 2009.

5. Joshi K, Shankar SK, Gopinath N, Kumar R and Chopra P: Multiple sclerosing haemangiomas of the lung. Postgrad Med J 56: 50-53, 1980.

6. Tanaka I, Inoue M, Matsui $\mathrm{Y}$, Oritsu S, Akiyama O, Takemura T, Fujiwara M, Kodama T and Shimosato Y: A case of pneumocytoma (so-called sclerosing hemangioma) with lymph node metastasis. Jpn J Clin Oncol 16: 77-86, 1986.
7. Chan AC and Chan JK: Pulmonary sclerosing hemangioma consistently expresses thyroid transcription factor-1 (TTF-1): a new clue to its histogenesis. Am J Surg Pathol 24: 1531-1536, 2000.

8. Devouassoux-Shisheboran M, Hayashi T, Linnoila RI, Koss MN and Travis WD: A clinicopathologic study of 100 cases of pulmonary sclerosing hemangioma with immunohistochemical studies: TTF-1 is expressed in both round and surface cells, suggesting an origin from primitive respiratory epithelium. Am J Surg Pathol 24: 906-916, 2000

9. Yano M, Yamakawa Y, Kiriyama M, Hara M and Murase T: Sclerosing hemangioma with metastases to multiple nodal stations. Ann Thorac Surg 73: 981-983, 2002

10. Miyagawa-Hayashino A, Tazelaar HD, Langel DJ and Colby TV: Pulmonary sclerosing hemangioma with lymph node metastases: report of 4 cases. Arch Pathol Lab Med 127: 321-325, 2003.

11. Chan NG, Melega DE, Inculet RI and Shepherd JG: Pulmonary sclerosing hemangioma with lymph node metastases. Can Respir J 10: 391-392, 2003.

12. Kim KH, Sul HJ and Kang DY. Sclerosing hemangioma with lymph node metastasis. Yonsei Med J 44: 150-154, 2003.

13. Kim GY, Kim J, Choi YS, Kim HJ, Ahn G and Han J: Sixteen cases of sclerosing hemangioma of the lung including unusual presentations. J Korean Med Sci 19: 352-358, 2004.

14. Katakura H, Sato M, Tanaka F, Sakai H, Bando T, Hasegawa S, Nakashima Y and Wada H: Pulmonary sclerosing hemangioma with metastasis to the mediastinal lymph node. Ann Thorac Surg 80: 2351-2353, 2005.

15. Vaideeswar P: Sclerosing hemangioma with lymph nodal metastases. Indian J Pathol Microbiol 52: 392-394, 2009.

16. Ymazaki A, Masuda S, Ose Y, Tahara M, Nakahara K, Hayashi I: Sclerosing hemangioma in right lung with lymph node metastasis. In: Proceedings of the 124th Kanto Branch Congress of the Japan Lung Cancer Society, Tokyo. The Japan Lung Cancer Society, Tokyo, pp223, 1999.

17. Katakura H, Sakai H, Tanaka H, Chin T, Ogawa E, Ri M, Kawashima M, Yanagihara K, Hanaoka S, Bando T, Hasegawa S, Wada $\mathrm{H}$ : A case of pulmonary sclerosing hemangioma with lymph node metastasis. In: Proceedings of the 78th Kansai Branch Congress of the Japan Lung Cancer Society, Osaka. The Japan Lung Cancer Society, Tokyo, pp768, 2003.

18. Nakajima D, Sumitomo S, Matsumoto K, Tarumi S, Mori N, Sumitomo R: A case of pulmonary sclerosing hemangioma with lymph node metastasis (Japanese). Nippon Kokyuki Geka Gakkai Zasshi 24: 74-77, 2010.

19. Kita H, Shiraishi Y, Katsushiro N, Hyougotani A, Hiramatsu M, Shimoda K: A case of sclerosing hemangioma with lymph node metastasis. In: Proceedings of the 52nd Congress of the Japan Lung Cancer Society, Osaka. The Japan Lung Cancer Society, Tokyo, pp618, 2011. 